Article

\title{
Analytical Parameters of an Amperometric Glucose Biosensor for Fast Analysis in Food Samples
}

\author{
Margalida Artigues (1), Jordi Abellà (1) and Sergi Colominas * \\ Electrochemical Methods Laboratory-Analytical and Applied Chemistry Department, \\ ETS Institut Químic de Sarrià, Universitat Ramon Llull, Via Augusta, 390, 08017 Barcelona, Spain; \\ margalida.artigues@iqs.edu (M.A.); jordi.abella@iqs.edu (J.A.) \\ * Correspondence: sergi.colominas@iqs.edu; Tel.: +34-932-672-108
}

Received: 28 September 2017; Accepted: 6 November 2017; Published: 14 November 2017

\begin{abstract}
Amperometric biosensors based on the use of glucose oxidase (GOx) are able to combine the robustness of electrochemical techniques with the specificity of biological recognition processes. However, very little information can be found in literature about the fundamental analytical parameters of these sensors. In this work, the analytical behavior of an amperometric biosensor based on the immobilization of GOx using a hydrogel (Chitosan) onto highly ordered titanium dioxide nanotube arrays $\left(\mathrm{TiO}_{2} \mathrm{NTAs}\right)$ has been evaluated. The GOx-Chitosan $/ \mathrm{TiO}_{2} \mathrm{NTAs}$ biosensor showed a sensitivity of $5.46 \mu \mathrm{A} \cdot \mathrm{mM}^{-1}$ with a linear range from 0.3 to $1.5 \mathrm{mM}$; its fundamental analytical parameters were studied using a commercial soft drink. The obtained results proved sufficient repeatability $(\mathrm{RSD}=1.9 \%)$, reproducibility $(\mathrm{RSD}=2.5 \%)$, accuracy $(95-105 \%$ recovery), and robustness $(\mathrm{RSD}=3.3 \%)$. Furthermore, no significant interferences from fructose, ascorbic acid and citric acid were obtained. In addition, the storage stability was further examined, after 30 days, the GOx-Chitosan $/ \mathrm{TiO}_{2}$ NTAs biosensor retained $85 \%$ of its initial current response. Finally, the glucose content of different food samples was measured using the biosensor and compared with the respective HPLC value. In the worst scenario, a deviation smaller than $10 \%$ was obtained among the 20 samples evaluated.
\end{abstract}

Keywords: biosensor; chitosan; glucose oxidase; glucose quantification

\section{Introduction}

The high sugar consumption in the modern diet has been commonly associated with chronic health consequences including risk of obesity, diabetes, cardiovascular disease, and fatty liver disease [1]. Nowadays, two out of three adults and one out of three children in the United States are overweight or obese [2,3] due to the high level of sugar consumption. In the same way, in the European Union 52\% of the adult population is now overweight, of which $17 \%$ is obese and more than $15 \%$ of adolescents in southern European countries are obese [4].

It is also worth mentioning that in the food industry more manufacturing processes are used routinely, and more sophisticated quality control methods are needed to ensure that every ingredient maintains its quality and safety through all processing stages. As a result, analytes like sugars, alcohols, phenols, oligonucleotides, and $\mathrm{O}_{2}$ need to be measured at multiple stages of the production process and also in the final product. Moreover, the increasing number of food safety regulations related to alimentary allergens and contaminants require extensive control of different analytes, such as lactose [5] or glutamate [6] among others [7].

Numerous methods are reported for these analyses in food [8-11]; among them, Colorimetry and High-Performance Liquid Chromatography (HPLC) are well-established and accepted tools for glucose determination in food matrices. However, most of the adopted methods are time consuming, 
expensive and require specialized personnel. In addition, the presence of interfering species in the sample matrix implies complex sample preparation processes, such as solid phase extraction (SPE) or chemical modifications (e.g., fluorescent functionalization). These sample treatments increase the complexity, time, and cost of the analysis. Therefore, development of fast, cheap, practical, and selective methods for detecting glucose in food is still a research area. In this context, electrochemical biosensors have attracted much attention due to their promising characteristics that fulfill these market demands. Moreover, due to their outstanding features, sensors presenting nano-engineered electrochemical interfaces have gained interest.

Leland C. Clark Jr. and Champ Lyons introduced in 1962 the principle of the first enzyme electrode with immobilized glucose oxidase [12]. Following some improvements, the biosensor was launched onto the market in 1975 by the Yellow Springs Instruments Co. (Yellow Springs, OH, USA). This device was specifically designed and used for fast glucose analysis in blood samples from diabetics. Since then, the biosensor field has experienced important growth. In this context, amperometric glucose biosensors offer great potential for their use in the food production and processing industry.

Amperometric glucose biosensors are prepared by immobilizing glucose oxidase (GOx) molecules onto an electrochemical interface. The enzyme catalyzes the conversion of glucose to gluconic acid and hydrogen peroxide. Glucose is quantified by the electrochemical measurement of hydrogen peroxide. One of the most important factors for the proper functioning of the biosensor is the correct selection of the electrochemical interface where the enzyme is immobilized. Recent researchers focused on the use of electrical conductors or semiconductor nanomaterials as biosensor interfaces $[13,14]$. The high surface area of nanomaterials allows immobilization of a large number of enzyme molecules, significantly increasing the sensitivity of the sensor [15]. Among all nanomaterials, titanium dioxide has been one of the most interesting materials in recent investigations $[16,17]$ due to the facility to control the morphology of highly ordered titanium dioxide nanotube arrays ( $\mathrm{TiO}_{2} \mathrm{NTAs}$ ). Moreover, biocompatibility and ability to promote charge transfer processes make this material suitable as an electrochemical interface $[18,19]$.

$\mathrm{TiO}_{2}$ NTAs are formed by anodization from bare titanium [20-22]. In fluoride-containing electrolytes, the anodization of $\mathrm{Ti}$ is accompanied with the chemical dissolution of $\mathrm{TiO}_{2}$ due to the formation of $\mathrm{TiF}_{6}{ }^{2-}$ anions [23]. This formation process ends when $\mathrm{TiO}_{2}$ dissolution and formation rates reach the equilibrium. Due to the simplicity of the anodic formation as well as for all the $\mathrm{TiO}_{2} \mathrm{NTAs}$ properties, it has been extensively used as electrical interface for biosensor applications [14,17,18,24-26].

An important factor for the success of an enzymatic biosensor is the enzyme immobilization strategy. This process provides an intimate contact between the enzyme and the electrode surface. The objective is to maintain or improve the enzyme stability, properties, and the active structural conformation, as well as to allow the substrate to arrive at the active center of the enzyme [27]. Different physical and chemical immobilization techniques can be used to achieve this goal: surface adsorption, electrostatic interactions, covalent binding or polymer entrapment [28-31]. One of the simplest approaches is to entrap the enzyme within a gel layer, for example using Chitosan which is a biocompatible and biodegradable hydrogel [32-34] and contributes to stabilizing the enzyme molecules [31,35].

Several biosensor designs can be found in literature for glucose analysis in food stuff [36-43]. Usually, authors focus their efforts on new architectures to overcome matrix interferences or to modify the sensors' linear range and sensitivity, as well as to keep the enzyme active as long as possible. However, there is a general lack of information in literature on other fundamental analytical parameters, like specificity, precision, accuracy, and robustness. These parameters must be deeply evaluated to prove both that a new measuring method or tool is capable of producing accurate results and to fulfill the quality assurance requirements of the food industry.

The goal of this work is to evaluate the analytical parameters of a biosensor to measure glucose in four different food products: soft drinks, soy sauces, dairy products and tomato sauces. The analyses have been performed using an amperometric glucose biosensor based on GOx immobilization with a 
polymeric hydrogel (Chitosan) onto highly ordered titanium dioxide nanotube arrays $\left(\mathrm{TiO}_{2} \mathrm{NTAs}\right)$. This sensor architecture was selected due to its simplicity and relative low cost.

\section{Materials and Methods}

Titanium (99.7\%, $5 \mathrm{~mm}$ diameter) was supplied by Alfa Aesar (Black Friel, MA, USA). Ethylene glycol (EG), ammonium fluoride and hydrogen peroxide were supplied by Panreac. Glucose, GOx (type: VII, Aspergillus niger, 100 units/mg) (ref. 101404648) and a low molecular weight Chitosan (ref. 1001654970) were supplied by Sigma Aldrich. The supporting electrolyte was $0.1 \mathrm{M} \mathrm{pH} \mathrm{7.0}$ phosphate buffer solution (PBS).

The electrode morphology was characterized using a field emission scanning electron microscope (JEOL JSM-7001F, Tokyo, Japan). Linear sweep and amperometric measurements were performed in a standard three-electrode configuration $(\mathrm{Ag} / \mathrm{AgCl} / 3 \mathrm{M} \mathrm{KCl}$ was used as a reference electrode). All potentials mentioned in this work are referred to as the reference electrode. Experiments were performed using a potentiostat Autolab PGSTAT 302N and the working electrode was mounted in a rotating disc electrode system EG\&G PARC model 616.

\subsection{Synthesis of $\mathrm{TiO}_{2}$ Nanotubes Array}

$\mathrm{TiO}_{2}$ nanotubes arrays were synthesized onto the Ti substrates by anodic oxidation. First of all, pure titanium disks were polished with SiC paper (2000 grit) and then were cleaned in ethanol prior to anodization. The cleaned Ti disks were anodized in a two-electrode electrochemical cell in ethylene glycol solution containing $0.3 \% \mathrm{NH}_{4} \mathrm{~F}$ and $2 \% \mathrm{H}_{2} \mathrm{O}$ at $35 \mathrm{~V}$ for $17 \mathrm{~h}$. This anodization time yields the maximum sensitivity of the sensor. Higher times result in the nanotube walls collapse. Then, the prepared electrode was sonicated during $30 \mathrm{~s}$ in water to remove surface debris. Finally, a thermal annealing was performed at $500{ }^{\circ} \mathrm{C}$ for $3 \mathrm{~h}$ in air to crystallize $\mathrm{TiO}_{2}$ nanotubes from amorphous to anatase phase [44].

\subsection{Preparation of the Biosensor}

The immobilization of GOx on the modified $\mathrm{TiO}_{2}$ nanotubes array electrode $\left(\mathrm{TiO}_{2} \mathrm{NTAs} / \mathrm{Ti}\right)$ was carried out by physical methods. An enzyme solution was prepared by dissolving $15 \mathrm{mg}$ of GOx in $500 \mu \mathrm{L}$ of $0.1 \mathrm{M}$ PBS (pH 7.0). Then, the enzyme solution was immobilized onto the modified electrode using the hydrogel Chitosan (see Figure 1).

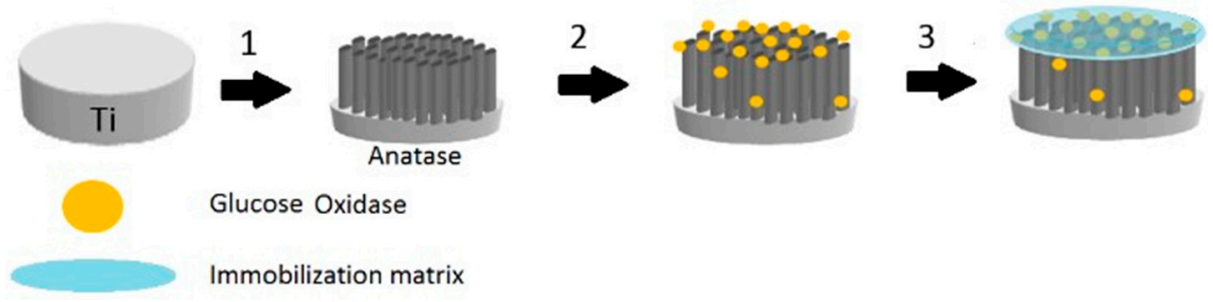

Figure 1. Scheme showing the construction of the glucose biosensor, step 1: growing and crystallization of titanium nanotubes; step 2: deposition of glucose oxidase molecules; and step 3: deposition of a polymeric cover (Chitosan) as immobilization matrix.

A $0.5 \%$ Chitosan solution was prepared by dissolving $53 \mathrm{mg}$ Chitosan in $1 \%$ acetic acid. $20 \mu \mathrm{L}$ of GOx solution and $20 \mu \mathrm{L}$ of Chitosan solution were deposited on a $\mathrm{TiO}_{2} \mathrm{NTAs} / \mathrm{Ti}$ electrode, then mixed and dried with an air stream. The obtained Chitosan-GOx/ $\mathrm{TiO}_{2} \mathrm{NTAs} / \mathrm{Ti}$ biosensor was washed with PBS to eliminate the enzyme that had not been immobilized. Finally, it was immersed in PBS solution for at least $30 \mathrm{~min}$ to rehydrate the enzyme molecules. When the electrodes were not in use, they were kept immersed in $0.1 \mathrm{M}$ PBS (pH 7.0) at $4{ }^{\circ} \mathrm{C}$. 


\subsection{Samples Preparation}

Samples for the amperometric biosensor measurements did not need further preparations than dilution. For the soft drinks and the soy sauces, an adequate volume of the sample was directly added to the measuring chamber, containing $100 \mathrm{~mL}$ of $0.1 \mathrm{M}$ PBS (pH 7.0). Dairy products and tomato sauces were first diluted into $50 \mathrm{~mL}$ of water. Then, an adequate volume of the diluted sample was directly added to the measuring chamber, containing $100 \mathrm{~mL}$ of $0.1 \mathrm{M}$ PBS (pH 7.0). All samples were quantified by the standard additions method.

\subsection{HPLC and Amperometric Measurements}

Glucose was determined by HPLC using an Agilent Technologies 1200 Series Chromatograph. Separation was done using a Kromasil ${ }^{\circledR} 100 \mathrm{NH}_{2}$ column with $5 \mu \mathrm{m}$ of particle size, $250 \mathrm{~mm}$ longitude and $4 \mathrm{~mm}$ inner diameter. Elution was with $75 \%$ acetonitrile in ultrapure water. Eluted components were detected using a refraction index detector (Agilent G1362A) and quantified by direct interpolation in a calibration curve.

Soft drink samples for the HPLC analysis were prepared by diluting $10 \mathrm{~mL}$ into $100 \mathrm{~mL}$ of ultrapure water and then were filtered through $0.45 \mu \mathrm{m}$ nylon filters. Dairy products, soy and tomato sauces were prepared by dissolving an adequate amount of sample into $50 \mathrm{~mL}$ of Milli-Q water, followed by $10 \mathrm{~min}$ ultrasonication. The resulting mixture was centrifuged at $5000 \mathrm{rpm}$ for $10 \mathrm{~min}$. The supernatant solutions were filtered through $0.22 \mu \mathrm{m}$ filters prior to injection.

Glucose was also quantified in the test sample using an amperometric/enzymatic titration method [45,46]. In this analytical method, GOx catalyzes the oxidation of glucose by dissolved oxygen to yield gluconic acid and hydrogen peroxide (Equation (1)). Then, hydrogen peroxide reacted with iodide to produce iodine in presence of molybdate as a catalyst (Equation (2)).

$$
\begin{gathered}
\text { Glucose }+\mathrm{O}_{2} \rightarrow \mathrm{H}_{2} \mathrm{O}_{2}+\text { Gluconic Acid } \\
\mathrm{H}_{2} \mathrm{O}_{2}+2 \mathrm{I}^{-}+2 \mathrm{H}^{+} \rightarrow \mathrm{I}_{2}+2 \mathrm{H}_{2} \mathrm{O}
\end{gathered}
$$

The iodine formation is followed continuously by monitoring the current in a two-electrode system (Pt electrodes) by applying a constant potential of $100 \mathrm{mV}$. Under these conditions, the slope of the curve current vs. time is proportional to the glucose concentration. Then, a calibration curve can be constructed by plotting the slopes vs. the glucose concentration. This method has been thoroughly explained in the literature $[45,46]$. The glucose content in the test sample was determined by direct interpolation in the calibration curve.

\section{Results and Discussion}

\subsection{Biosensor Construction and Determination of Its Optimal Working Conditions}

The morphology of the titanium substrate after anodization was studied by FE-SEM analysis (JEOL JSM-7001F). Figure 2 shows the ordered tubular structures obtained after anodization.

FE-SEM image (Figure 2) revealed that highly ordered and vertically aligned $\mathrm{TiO}_{2}$ nanotube array was obtained during the anodization process. The formed nanotubes had an open-mouth structure on the top of the $\mathrm{TiO}_{2}$ layer, with estimated average dimensions of $80 \mathrm{~nm}$ inner diameter and $10 \mathrm{~nm}$ wall-thickness. The pore size and regular hollow structure stem from the anodic oxidation process [18].

The glucose biosensor was fabricated by immobilizing GOx using Chitosan onto $\mathrm{TiO}_{2} \mathrm{NTAs} / \mathrm{Ti}$. This sensor architecture was selected due to its simplicity and relative low cost, as well as for the high active area that allows immobilization of a high number of enzyme molecules. Moreover, Chitosan and anatase phase provide high biocompatibility to the system which can improve the long-term stability of the biosensor [18,19,31-33]. 


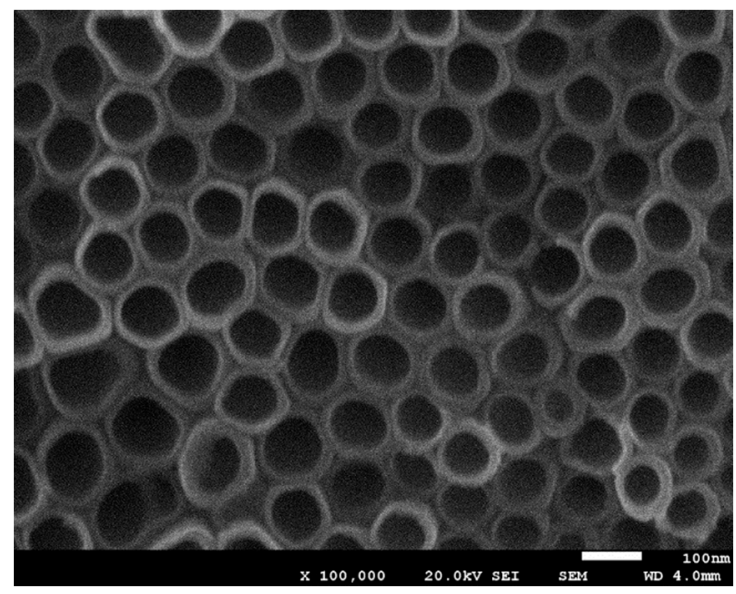

Figure 2. FE-SEM image of the formed $\mathrm{TiO}_{2}$ nanotube arrays.

Glucose quantification was performed indirectly by reducing hydrogen peroxide (generated by the enzymatic reaction) to water at the electrochemical interface $\left(\mathrm{TiO}_{2} \mathrm{NTAs} / \mathrm{Ti}\right)$. Two experiments were performed in order to evaluate $\mathrm{H}_{2} \mathrm{O}_{2}$ reduction over the $\mathrm{TiO}_{2} \mathrm{NTAs}$ / Ti electrochemical interface and glucose sensing with the Chitosan-GOx/ $\mathrm{TiO}_{2} \mathrm{NTAs} / \mathrm{Ti}$ biosensor. On one hand, $\mathrm{TiO}_{2} \mathrm{NTAs} / \mathrm{Ti}$ response in PBS containing $5 \mathrm{mM}$ of hydrogen peroxide was recorded and compared with bare titanium (see Figure 3A). On the other hand, Chitosan-GOx/ $\mathrm{TiO}_{2} \mathrm{NTAs} / \mathrm{Ti}$ biosensor response versus $5 \mathrm{mM}$ of glucose in $0.1 \mathrm{M}$ PBS was performed and compared with the $\mathrm{TiO}_{2} \mathrm{NTAs} / \mathrm{Ti}$ (see Figure 3B).
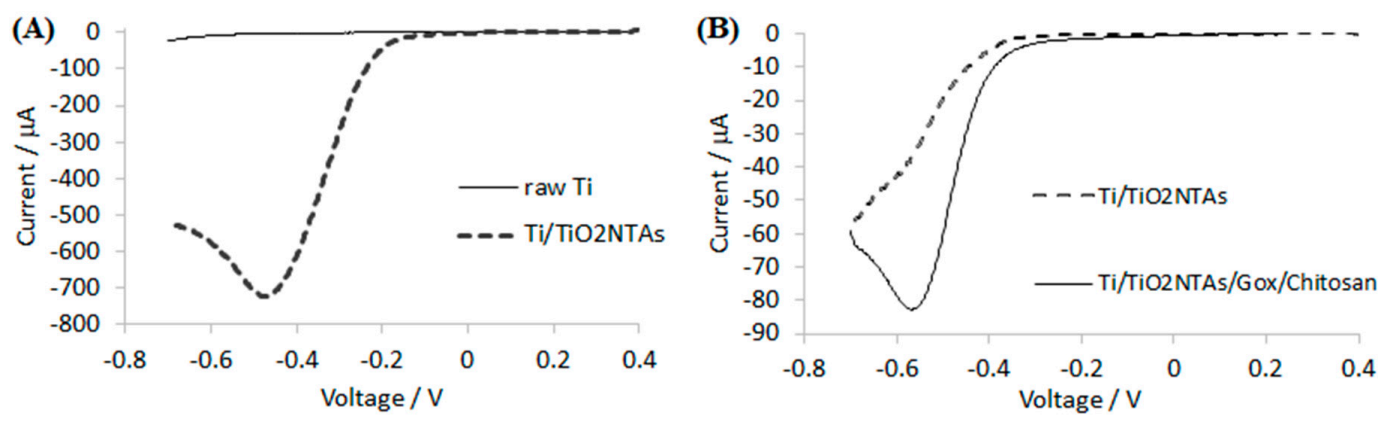

Figure 3. Linear sweep voltammograms of (A) $\mathrm{Ti}$ and $\mathrm{Ti} / \mathrm{TiO}_{2} \mathrm{NTAs}$ sensors in PBS with $5 \mathrm{mM} \mathrm{H}_{2} \mathrm{O}_{2}$ and (B) $\mathrm{Ti} / \mathrm{TiO}_{2} \mathrm{NTAs}$ sensor and Chitosan-GOx/ $\mathrm{TiO}_{2} \mathrm{NTAs} / \mathrm{Ti}$ biosensor in PBS with $5 \mathrm{mM}$ glucose. Scan rate: $100 \mathrm{mV} \cdot \mathrm{s}^{-1}$.

As can be seen in Figure 3A, the reduction of $\mathrm{H}_{2} \mathrm{O}_{2}$ was registered in both cases at potentials lower than $-0.2 \mathrm{~V}$. Bare Ti shows a reduction peak at $-0.47 \mathrm{~V}$ and $-3.5 \mu \mathrm{A}$, while the $\mathrm{Ti} / \mathrm{TiO}_{2} \mathrm{NTAs}$ shows a higher reduction peak at the same potential $(-723.0 \mu \mathrm{A})$. The presence of the $\mathrm{Ti} / \mathrm{TiO}_{2} \mathrm{NTAs}$ increases the substrate response by a factor of 200 approximately. The difference in peak current is due to two different factors: the increase of the active surface area of the electrode and the catalytic activity of $\mathrm{TiO}_{2}$ through $\mathrm{H}_{2} \mathrm{O}_{2}$ reduction [47].

In order to evaluate the working potential of the Chitosan- $\mathrm{GOx} / \mathrm{TiO}_{2} \mathrm{NTAs} / \mathrm{Ti}$ biosensor, linear sweep volammetries were performed in PBS containing $5 \mathrm{mM}$ glucose (see Figure 3B). The Chitosan-GOx/ $/ \mathrm{TiO}_{2} \mathrm{NTAs} / \mathrm{Ti}$ biosensor was compared with $\mathrm{Ti} / \mathrm{TiO}_{2} \mathrm{NTAs}$. It can be seen in Figure $3 \mathrm{~B}$ that the presence of the enzyme immobilized on the electrical interface showed glucose response at potentials more cathodic than $-0.2 \mathrm{~V}$. This electrochemical activity is related to the hydrogen peroxide reduction generated by the enzyme in the presence of glucose. The biosensor showed a cathodic peak current of $-82.8 \mu \mathrm{A}$ at $-0.57 \mathrm{~V}$. To select the working potential applied to the biosensor two considerations were required: the first was to assure $\mathrm{H}_{2} \mathrm{O}_{2}$ reduction to $\mathrm{H}_{2} \mathrm{O}$ at the 
electrochemical interface and the second was to prevent enzyme denaturalization. Taking into account these considerations, it was decided to set the working potential at $-0.4 \mathrm{~V}$ vs. $\mathrm{Ag} / \mathrm{AgCl}$.

\subsection{Analytical Parameters of Chitosan-GOx/TiO 2 NTAs/Ti Biosensor}

The evaluation of the analytical quality parameters is essential to ensure that the methodology is accurate, specific, reproducible and robust over the specified range where an analyte will be determined [48]. Furthermore, the Food and Drug Administration (FDA) requires to determine these analytical parameters in order to guarantee the reliability of the analytical results [49].

First of all, the glucose content of a test sample (a commercial lemon soft drink) was determined using high-performance liquid chromatography (HPLC), amperometric/enzymatic titration [45,46] and Chitosan-GOx/ $/ \mathrm{TiO}_{2} \mathrm{NTAs} / \mathrm{Ti}$ biosensor. The goal of this initial step was to assure the biosensor measurement is in good agreement with other classical analytical techniques. Glucose was determined by HPLC by performing 2 replicate measurements. The obtained glucose concentration in the test sample was $0.14 \mathrm{M}$. Glucose was also quantified in the test sample using the amperometric/enzymatic titration method $[45,46]$ and the obtained glucose concentration was $0.15 \mathrm{M}$. Finally, a Chitosan-GOx/ $\mathrm{TiO}_{2} \mathrm{NTAs} / \mathrm{Ti}$ biosensor was constructed to determine the glucose concentration of the test sample using the standard additions method; the current was continuously measured in $100 \mathrm{~mL}$ PBS at pH 7.0 to record the blank signal, then an adequate volume of the sample was added and finally two additions of $0.25 \mathrm{mM}$ glucose standard solution were made. The obtained glucose concentration was $0.15 \mathrm{M}$.

To summarize, all glucose concentrations are shown in Table 1. In addition, the standard deviation (s) and the relative standard deviation (RSD\%) of the measurements are included in the table.

Table 1. Determination of glucose in a lemon soft drink using different analytical techniques.

\begin{tabular}{cccc}
\hline Method & [Glucose]/M & s/M & RSD/\% \\
\hline HPLC & 0.14 & $1.23 \times 10^{-3}$ & 0.9 \\
Amperometric & 0.15 & $3.15 \times 10^{-3}$ & 2.1 \\
Proposed biosensor & 0.15 & $2.02 \times 10^{-3}$ & 1.3 \\
\hline
\end{tabular}

As can be seen in Table 1, the glucose content using HPLC and the amperometric/enzymatic method were in good agreement with the result obtained using the biosensor. The glucose concentration determined by HPLC $(0.14 \mathrm{M})$ showed a deviation of $6.4 \%$ with respect to the glucose content determined by the biosensor. Using the amperometric/enzymatic method this deviation was even smaller $(1.6 \%)$. It can be seen that there is a good agreement between the determinations performed using the biosensor and the results obtained using HPLC and the amperometric/enzymatic method.

\subsubsection{Evaluation of the Linear Range, Limit of Detection (LOD) and Limit of Quantification (LOQ)}

The amperometric response of Chitosan- $\mathrm{GOx} / \mathrm{TiO}_{2} \mathrm{NTAs} / \mathrm{Ti}$ biosensor to continuous injections of $0.3 \mathrm{mM}$ glucose in $0.1 \mathrm{M}$ PBS (pH 7.0) at $-0.4 \mathrm{~V}$ vs. ref., was studied under a forced convection regime of the working RDE at $2000 \mathrm{rpm}$. Figure 4 shows the measured current over time after each glucose addition.

As can be seen in Figure 4, the registered current after each glucose addition $(0.3 \mathrm{mM})$ increased approximately $2 \mu \mathrm{A}$. In order to determine the linear range of the Chitosan-GOx/ $\mathrm{TiO}_{2} \mathrm{NTAs} / \mathrm{Ti}$ biosensor, a calibration curve was built plotting the corrected current vs. the glucose concentration. The corrected current was calculated as the registered current after each glucose addition minus the blank signal (PBS). The obtained calibration curve had a slope equal to $5.46 \mu \mathrm{A} \cdot \mathrm{mM}^{-1}$ and an intercept of $0.67 \mu \mathrm{A}$. A linear relationship of the corrected current to the glucose concentration was obtained between $0.3 \mathrm{mM}$ and $1.5 \mathrm{mM}$ glucose, with a correlation coefficient of 0.9902 . 


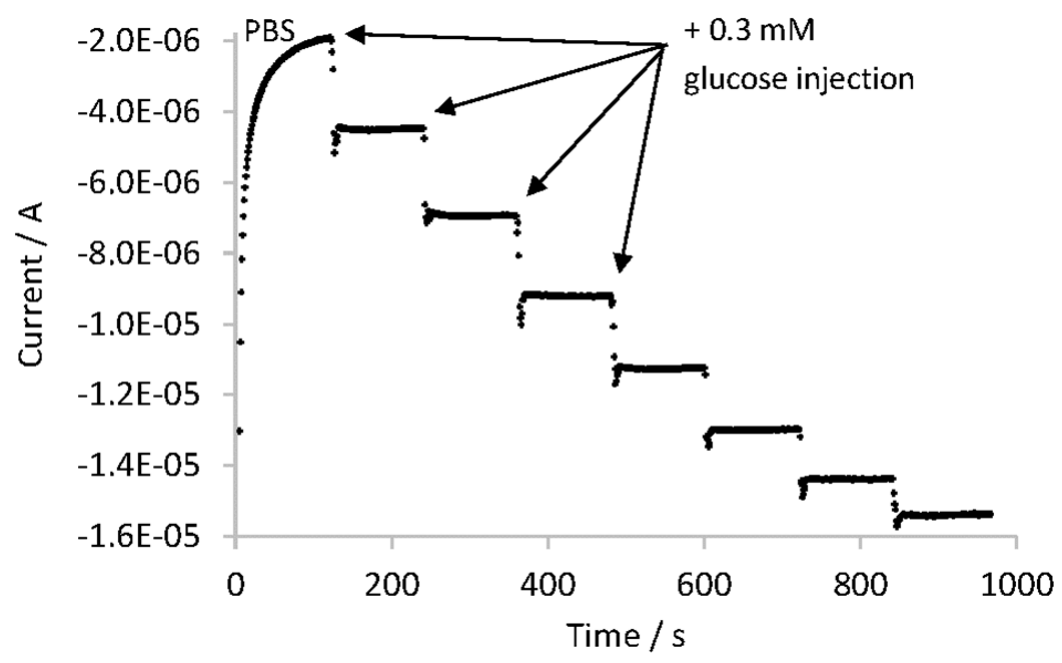

Figure 4. Current-time plot of Chitosan-GOx/ $\mathrm{TiO}_{2} \mathrm{NTAs} / \mathrm{Ti}$ biosensor with applied potential of $-0.4 \mathrm{~V}$ when $0.3 \mathrm{mM}$ glucose injections were done.

The slope of the calibration curve was associated to the biosensors sensitivity which is related to the limit of detection (LOD). The LOD was defined as the concentration that can be detected at 3 times the noise level and it was of $0.07 \mathrm{mM}$ in glucose. This value is in good agreement with other LODs reported in literature $[50,51]$ for similar glucose biosensors. In addition, the limit of quantification (LOQ) was also calculated, defined as the concentration that can be detected at 10 times the noise level and it was equal to $0.30 \mathrm{mM}$ in glucose.

The linear range and sensitivity of the Chitosan-GOx/ $\mathrm{TiO}_{2} \mathrm{NTAs} / \mathrm{Ti}$ biosensor were compared with reported results of other glucose biosensors in literature (see Table 2).

Table 2. Some examples of glucose oxidase biosensors reported in the literature. The biosensor final application, sensitivity and linear range values are shown.

\begin{tabular}{ccccc}
\hline Schematic Biosensor Assembly & Sample Type & Linear Range/mM & Sensitivity/ $\boldsymbol{\mu A} \cdot \mathbf{m M}^{-\mathbf{1}}$ & Reference $^{-}$ \\
\hline GCE/PB/PDA-GOx & Physiological samples & $0.2-3.4$ & 1.59 & {$[52]$} \\
Gr/PANI/AuNPs/GOx & Whole blood & $0.2-11.2$ & 4.58 & {$[53]$} \\
SPCE/PPy/CNC/GOx & - & $1.0-20$ & 0.73 & {$[54]$} \\
GOx/PMPD-PB/GC & Serum samples & $0.025-0.65$ & 2.54 & {$[55]$} \\
Cellulose/GOx/PB-SPCE & Beverages & $0.25-2.00$ & 2.14 & {$[56]$} \\
GOx/AuPd/PI/RGO & Human serum & $0.024-4.6$ & 2.82 & {$[57]$} \\
GA-GOx/Pt & Bioprocesses monitoring & $0.01-20$ & 1.47 & {$[58]$} \\
Chitosan-GOx/TiO ${ }_{2}$ NTAs/Ti & Food samples & $0.3-1.5$ & 5.46 & Present work \\
\hline
\end{tabular}

AuNPs, gold nanoparticles; CNC, cellulose nanocrystal; GA, glutaraldehyde; GCE, glassy carbon electrode; $\mathrm{Gr}$, graphene; PANI, polyaniline; PB, Prussian Blue; PDA, polymerized dopamine; PMPD, poly(m-phenylenediamine); PPy, polypyrrole; SPCE, screen printed carbon electrode.

As can be seen in Table 2, the proposed biosensor achieved high sensitivity values $\left(5.46 \mu \mathrm{A} \cdot \mathrm{mM}^{-1}\right)$, in comparison with other similar glucose amperometric biosensors reported in literature. This may result from the intrinsic structure of the Chitosan-GOx/ $\mathrm{TiO}_{2} \mathrm{NTAs} / \mathrm{Ti}$ electrode, which was able to retain a high number of enzyme molecules and conserve their active structure. On the one hand, $\mathrm{TiO}_{2}$ offers excellent biocompatibility and large active surface area to successfully immobilize a high number of GOx molecules. On the other hand, the Chitosan affinity to proteins prevents enzyme denaturalization, offering an enzyme friendly environment. Thus, high electrochemical activity was achieved due to the positive interaction of the electrochemical interface $\left(\mathrm{TiO}_{2} \mathrm{NTAs}\right)$ and the immobilization matrix hydrogel (Chitosan) with the enzyme.

When an analytical method is optimized, an increase in the sensitivity results in a shrinkage of the dynamic linear range [59]. In comparison with other reported biosensors in literature, the proposed 
biosensor has a smaller linear range (see Table 2$)$, however it has a higher sensitivity $\left(5.46 \mu \mathrm{A} \cdot \mathrm{mM}^{-1}\right)$. As a result, the linear range is smaller. It is worth mentioning that it is possible to control the sensor sensitivity on the suggested biosensor by decreasing the anodization time. It yields shorter nanotubes and as a result a smaller active area. Thus, in order to expand the linear range, the sensor sensitivity can be decreased by a diminution of anodization time. However, this factor was not considered in the present study.

\subsubsection{Evaluation of Precision: Repeatability and Reproducibility}

In order to evaluate the repeatability of the method, five replicate measurements of the glucose content in the lemon soft drink sample were performed during the same laboratory session using the biosensor (see Table S1, Supplementary Materials). The average glucose concentration of the sample was $0.15 \mathrm{M}$, with a relative standard deviation (RSD\%) equal to $0.8 \%$. Taking into account that the RSD is lower than $1.9 \%$ (reference value suggested by the Association of Analytical Communities-AOAC [60]), it can be considered that measurements made with Chitosan-GOx/ $\mathrm{TiO}_{2} \mathrm{NTAs} / \mathrm{Ti}$ biosensor are repeatable.

Furthermore, sensor reproducibility was evaluated by measuring the glucose content of the test sample on five different days (see Table S2, Supplementary Materials). The average glucose content of test sample was $0.15 \mathrm{M}$ with a $2.5 \%$ RSD. Therefore, this procedure also accomplishes the reproducibility requirements suggested by the Association of Analytical Communities-AOAC $(<4 \%)[61]$.

\subsubsection{Evaluation of Accuracy}

The accuracy of an analytical method is calculated as the percentage of recovery by the assay of the known added amount of analyte in the sample. It is necessary to perform at least nine determinations at three different analyte concentration levels [62]. The accuracy of the biosensor method was evaluated by adding $80 \%, 100 \%$ and $120 \%$ of the target concentration to a blank sample. For this purpose, a glucose free soft drink of the same type and brand of the analyzed test sample was used as a blank solution. Table 3 shows the recovery of the tested samples.

Table 3. Recovery of glucose in prepared lemon soft drink samples.

\begin{tabular}{cccc}
\hline Level & Nominal [Glucose]/M & Found [Glucose] $\pm \mathbf{s} / \mathbf{M}$ & Recovery/\% \\
\hline $80 \%$ & 0.120 & $0.122 \pm 0.0015$ & 102 \\
$100 \%$ & 0.150 & $0.154 \pm 0.0020$ & 103 \\
$120 \%$ & 0.180 & $0.187 \pm 0.0027$ & 104 \\
\hline
\end{tabular}

As it is seen in Table 3, the results were well agreed with the nominal glucose concentration values. The recoveries obtained of the prepared samples were comprised between 95\% and 105\% [63] (reference value suggested by the Association of Analytical Communities-AOAC).

Moreover, an additional set of recovery assays was performed: two known amounts of glucose were added to the sample to achieve a glucose concentration of a $120 \%$ and a $140 \%$ of the nominal concentration. Results of added samples are shown in Table 4.

Table 4. Recovery of glucose in added lemon soft drink samples.

\begin{tabular}{ccccc}
\hline Level & Added [Glucose]/M & Nominal [Glucose]/M & Found [Glucose] \pm s/M & Recovery/\% \\
\hline $120 \%$ & 0.030 & 0.186 & $0.191 \pm 0.0025$ & 103 \\
$140 \%$ & 0.060 & 0.216 & $0.227 \pm 0.0018$ & 105 \\
\hline
\end{tabular}


Results in Table 4 show that the recovery rates were between $95 \%$ and $105 \%$ as in the previous situation. The satisfying results demonstrated that the Chitosan-GOx/ $\mathrm{TiO}_{2} \mathrm{NTAs} / \mathrm{Ti}$ biosensor was capable to determine glucose with an acceptable degree of accuracy.

\subsubsection{Evaluation of Biosensor Selectivity}

In order to study the selectivity of the glucose biosensor, the effect of the common interfering substances was tested. Food samples, in particular fruit juices and soft drinks, contain different electrochemical active species that can modify the glucose signal. Some of the most common interferences are ascorbic acid, citric acid and other sugars such as fructose [36,64]. The effect of these three substances was studied in the selectivity test. The response of the Chitosan-GOx/ $\mathrm{TiO}_{2} \mathrm{NTAs} / \mathrm{Ti}$ sensor to sequential injections of $0.25 \mathrm{mM}$ glucose and $0.25 \mathrm{mM}$ fructose, $0.25 \mathrm{mM}$ citric acid and $0.025 \mathrm{mM}$ ascorbic acid in PBS solution was studied (see Figure 5). The ratio between the glucose and the interfering species concentration was previously selected according to its concentration in the test sample and the dilution factor in the quantification process.
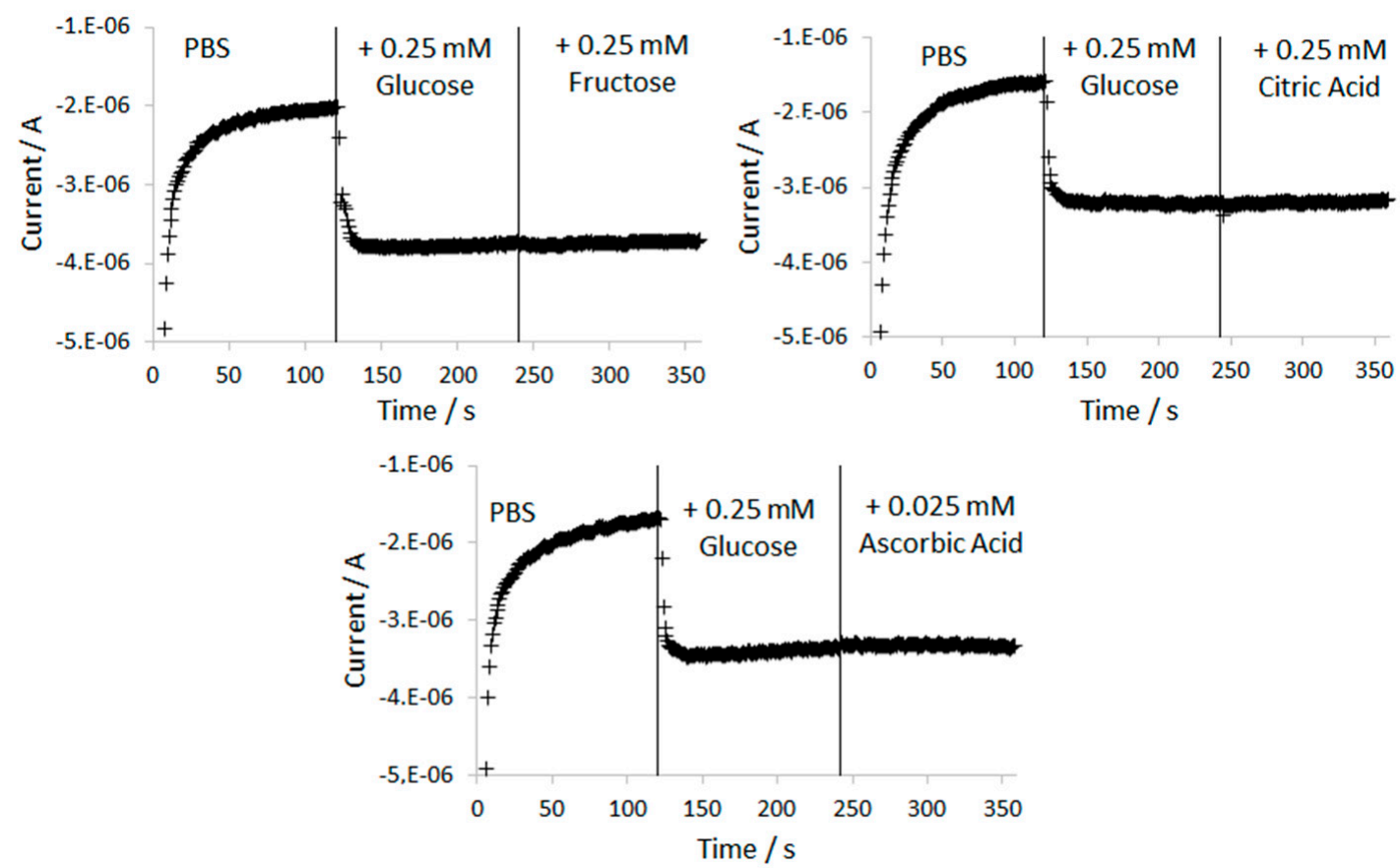

Figure 5. Amperometric responses of the Chitosan-GOx/ $\mathrm{TiO}_{2} \mathrm{NTAs} / \mathrm{Ti}$ biosensor measured in $0.1 \mathrm{M}$ PBS $\mathrm{pH} 7.0$ at potential of $-0.4 \mathrm{~V}$ vs. $\mathrm{Ag} / \mathrm{AgCl}$ with the addition of $0.25 \mathrm{mM}$ glucose and $0.25 \mathrm{mM}$ fructose (A); $0.25 \mathrm{mM}$ citric acid (B) and $0.025 \mathrm{mM}$ ascorbic acid (C) respectively.

As observed in Figure 5, when fructose, citric acid and ascorbic acid were added to the measuring solution, the current signals recorded by the biosensor were not affected. The biosensor exhibited strong response to $0.25 \mathrm{mM}$ of glucose, approximately $1.6 \mu \mathrm{A}$, the studied interferences gave no significant amperometric responses under the working conditions.

Conventional amperometric glucose biosensors commonly work applying anodic potentials in order to oxidize $\mathrm{H}_{2} \mathrm{O}_{2}$ to oxygen. Then, the obtained anodic current will be proportional to the glucose concentration. Under these experimental conditions reductive species such as ascorbic acid, can be oxidized at the working electrode and thus the obtained current will be increased. Physical permselective barriers, such as Nafion, are commonly used in conventional glucose biosensors to block the access of this type of interfering species at the electrode surface [65]. This type of polymers may cause a loss of enzyme due to the instability of the enzyme in contact with the Nafion membrane [66]. As a result, the sensitivity of the analytical procedure will be decreased. However, in 
the Chitosan-GOx/ $/ \mathrm{TiO}_{2} \mathrm{NTAs} / \mathrm{Ti}$ biosensor the working principle is the $\mathrm{H}_{2} \mathrm{O}_{2}$ reduction to $\mathrm{H}_{2} \mathrm{O}$ using a cathodic potential. Under this condition, the change in the measured current is minimal due to the addition of ascorbic acid, as was previously demonstrated (see Figure 4), so it can be considered as a minor interference. In addition, it is worth mentioning that the biosensor constructed using a chitosan barrier offers an extra advantage which is the high sensitivity of the analytical procedure. This fact is explained due to the high biocompatibility and affinity of Chitosan to proteins, which favors the protection of the enzyme molecules [32].

\subsubsection{Evaluation of Robustness}

Robustness is defined as the capacity of the analytical procedure to remain unaffected by small but deliberate deviations in the method parameters and provides an indication of its reliability during normal usage [49]. Robustness can also be described as the ability to reproduce the analytical method under different circumstances without the occurrence of unexpected differences in the obtained results. In this specific case, robustness refers to the entire process from the construction of the biosensor to the final glucose measurement.

In order to test the method robustness, five new biosensors were built; for each biosensor an

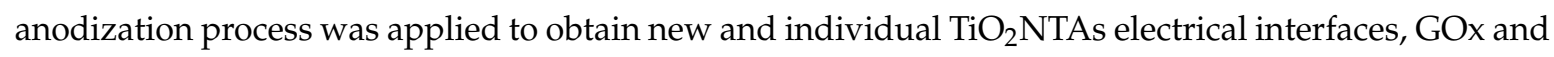
Chitosan solutions were freshly prepared for each individual biosensor and the glucose concentration in the sample was measured using each one of the five biosensors. Therefore, all the factors that could affect the fabrication of the biosensor were considered in the robustness test. These five new biosensors were used to quantify the glucose present in the sample over five different days (see Table S3, Supplementary Materials). The average glucose concentration obtained in the robustness test is $0.15 \mathrm{M}$ with a RSD of 3.3\%. This value indicates that the whole method, including the sensor construction and the measurement process is repeatable, reproducible, and robust.

\subsubsection{Evaluation of Storage Stability}

Another important requirement of a biosensor is the long-term stability. Amperometric biosensors have commonly two disadvantages which affect their life time; enzyme leakage and enzyme denaturalization [67]. Therefore, the biosensor stability was evaluated by comparing the slopes of the calibration curves (related to the sensitivity) measured on different days. Table 5 shows the change in the signal of the Chitosan-GOx/ $\mathrm{TiO}_{2} \mathrm{NTAs} / \mathrm{Ti}$ biosensor during the stability test.

Table 5. Study of variability between amperometric measurements done with Chitosan-GOx/ $\mathrm{TiO}_{2} \mathrm{NTAs} / \mathrm{Ti}$ biosensor on different days from their assembly.

\begin{tabular}{cccc}
\hline Time/Days & Slope/ $\boldsymbol{\mu A} \cdot \mathbf{m M}^{-\mathbf{1}}$ & $\mathbf{R}^{\mathbf{2}}$ & \% Signal Decrease \\
\hline 0 & 5.46 & 0.9902 & - \\
10 & 5.28 & 0.9902 & 3 \\
20 & 4.69 & 0.9904 & 14 \\
30 & 4.56 & 0.9903 & 15 \\
\hline
\end{tabular}

It can be seen in Table 5, Chitosan-GOx/ $\mathrm{TiO}_{2} \mathrm{NTAs} / \mathrm{Ti}$ biosensor retains an $85 \%$ of its initial sensitivity after 30 days from the first day measurement. This fact can be attributed to the excellent retention ability and good biocompatibility of the used immobilization matrix (Chitosan hydrogel). Chitosan forms a gel permeable to water with a high mechanical strength which, in combination with high affinity to proteins, favors the protection of the enzyme molecules [32]. Moreover, the obtained stability was similar to those of other glucose biosensors reported in literature which used Chitosan; after a month these biosensors retained between the $80 \%$ and the $90 \%$ of their initial response $[33,34,68]$.

AOAC prescribes the minimum analytical performance requirements of analytical methods for the quality control of food products. The analytical criteria established by this organization are highly demanding. In this context, classical analytical techniques, such as HPLC or spectrophotometry, 
are usually evaluated and used to guarantee the quality standards of foodstuff. However, these analytical tools are time consuming and expensive. For this reason, the Chitosan-GOx/ $\mathrm{TiO}_{2} \mathrm{NTAs} / \mathrm{Ti}$ biosensor was evaluated as an alternative to these classical analytical methods. In this work, it was demonstrated that all analytical parameters tested for this biosensor were in good agreement with the AOAC quality standards. Furthermore, the measurement method in the biosensor analysis is faster and simpler than the conventional methods for glucose analysis. Therefore, the studied sensor had a great potential for practical application and can be considered as a low-cost, simple and rapid alternative to the classical methods to quantify glucose in food samples for quality control.

\subsubsection{Measurement of Glucose in Food Samples}

The described Chitosan-GOx/ $/ \mathrm{TiO}_{2} \mathrm{NTAs} / \mathrm{Ti}$ biosensor was used to analyze the glucose concentration in four different alimentary products: soft drinks, soy sauces, tomato sauces and dairy products. The criteria selection of each sample matrix is to overcome interferences or quantification problems in classical techniques, such as HPLC. Soft drinks usually contain a high concentration of ascorbic acid and/or citric acid. Both species are classical interferents in the use of enzymatic methods. Soy sauces and tomato sauces are complex matrices with many elements in their composition that can influence the quantification process. It is worth mentioning that soy sauces present a high protein content and tomato sauces a high lipid content. Finally, dairy products were selected because of their high fat content. In addition, the presentence of lactose and galactose represents a common interference in the glucose determination using HPLC. In this study, the analyzed dairy samples were lactose free products. Therefore, this selection of samples depicts a large number of unfavorable situations for the glucose quantification in foodstuff. All selected samples were also analyzed by HPLC and the values obtained were considered as reference values. The results obtained with both analytical techniques are shown in Table 6.

Table 6. Determination of glucose in real food samples using the Chitosa- $\mathrm{GOx} / \mathrm{TiO}_{2} \mathrm{NTAs} / \mathrm{Ti}$ biosensor and a reference HPLC method. The deviation between both methods is also shown.

\begin{tabular}{|c|c|c|c|c|}
\hline Type of Sample & Sample & {$[\text { Glucose }]_{\text {biosensor }} \pm \mathrm{s} / \mathrm{M}$} & [Glucose] $_{\mathrm{HPLC} / \mathrm{M}}$ & Deviation/\% \\
\hline \multirow{8}{*}{ Soft drinks } & D1 Orange & $0.241 \pm 0.008$ & $0.251 \pm 0.001$ & -4.1 \\
\hline & D2 Lemon & $0.151 \pm 0.002$ & $0.141 \pm 0.001$ & 6.3 \\
\hline & D3 Lemon & $0.176 \pm 0.006$ & $0.189 \pm 0.001$ & -6.7 \\
\hline & D4 Orange & $0.215 \pm 0.019$ & $0.224 \pm 0.001$ & -4.0 \\
\hline & D5 Lemon & $0.212 \pm 0.011$ & $0.209 \pm 0.001$ & 1.4 \\
\hline & D6 Orange & $0.221 \pm 0.010$ & $0.232 \pm 0.001$ & -4.4 \\
\hline & D7 Cola & $0.156 \pm 0.008$ & $0.152 \pm 0.001$ & 2.3 \\
\hline & D8 Cola & $0.177 \pm 0.011$ & $0.168 \pm 0.007$ & 5.2 \\
\hline \multirow{5}{*}{ Soy sauces } & S1 & $0.520 \pm 0.025$ & $0.537 \pm 0.026$ & -3.1 \\
\hline & S2 & $0.089 \pm 0.005$ & $0.096 \pm 0.001$ & -7.3 \\
\hline & S3 & $0.250 \pm 0.004$ & $0.253 \pm 0.009$ & -1.5 \\
\hline & S4 & $0.745 \pm 0.003$ & $0.775 \pm 0.001$ & -3.8 \\
\hline & S5 & $0.093 \pm 0.003$ & $0.090 \pm 0.001$ & 2.7 \\
\hline \multirow{4}{*}{ Dairy products } & L1 Milk & $0.125 \pm 0.005$ & $0.134 \pm 0.001$ & -7.1 \\
\hline & L2 Milkshake & $0.170 \pm 0.006$ & $0.160 \pm 0.001$ & 6.1 \\
\hline & L3 Yoghurt & $0.142 \pm 0.006$ & $0.138 \pm 0.001$ & 2.7 \\
\hline & L4 Yoghurt & $0.125 \pm 0.004$ & $0.119 \pm 0.001$ & 5.4 \\
\hline \multirow{3}{*}{ Tomato sauces } & T1 Fried Tomato & $0.120 \pm 0.001$ & $0.111 \pm 0.003$ & 7.6 \\
\hline & T2 Fried Tomato & $0.092 \pm 0.003$ & $0.088 \pm 0.001$ & 4.9 \\
\hline & T3 Ketchup & $0.533 \pm 0.004$ & $0.515 \pm 0.007$ & 3.3 \\
\hline
\end{tabular}

As can be seen in Table 6, the glucose concentration of 20 different food samples with complex matrices was determined with sufficient precision using the biosensor. These results are in good agreement with those obtained by the HPLC method independently of the sample matrix. In all cases, 
the deviation between both methods was smaller than $10 \%$. Therefore, the biosensor was able to overcome all possible interferences in the selected samples. In addition, the obtained deviation values were smaller than most of the reported values in literature $[36,41,69,70]$. Usually, reported deviations are equal or higher than $10 \%$. Considering this and the short analysis time (approximately eight min per sample), the potential of the proposed biosensor for practical applications was demonstrated.

\section{Conclusions}

The analytical parameters of the Chitosan-Ox/ $\mathrm{TiO}_{2} \mathrm{NTAs} / \mathrm{Ti}$ biosensor were evaluated using a commercial lemon soft drink as a test sample. This biosensor showed a linear range from $0.3 \mathrm{mM}$ to $1.5 \mathrm{mM}$ of glucose with a low limit of detection $(0.07 \mathrm{mM})$, low limit of quantification $(0.30 \mathrm{mM})$ and high sensitivity $\left(5.46 \mu \mathrm{A} \cdot \mathrm{mM}^{-1}\right)$. The measured glucose concentration of the sample showed a good agreement with other analytical techniques: the deviation from HPLC was $6.4 \%$ and from an amperometric/enzymatic titration $1.6 \%$. Measurements done with the studied biosensor showed high repeatability (RSD equal to $0.8 \%$ ), high reproducibility (RSD equal to $2.5 \%$ ), high robustness and small analysis time (less than $10 \mathrm{~min}$ ). In addition, the biosensor had good selectivity towards common interfering species in food matrices, such us ascorbic acid, citric acid and fructose. Finally, the storage stability was further examined and after 30 days, the GOx-Chitosan $/ \mathrm{TiO}_{2} \mathrm{NTAs}$ biosensor retained $85 \%$ of its initial current response.

The biosensor was used to determine the glucose concentration in four different types of alimentary samples (soft drinks, soy sauces, dairy products and tomato sauces). In all the cases, the glucose concentration was determined with sufficient accuracy (deviation less than $10 \%$ ) regardless of the matrix composition. Therefore, it can be concluded that the electrochemical biosensor (Chitosan-GOx/ $\mathrm{TiO}_{2} \mathrm{NTAs} / \mathrm{Ti}$ ) represents as a low cost, simple and rapid alternative to classical methods for glucose quantification in foodstuff.

Supplementary Materials: The following are available online at http:/ /www.mdpi.com/1424-8220/17/11/2620/s1, Table S1: Study of the system repeatability. Measurements done during the same laboratory session; Table S2: Study of the system reproducibility. Measurements done during five days over five lemon samples; Table S3: Study of the method robustness. The measurements were done with five different Chitosan- $\mathrm{GOx} / \mathrm{TiO}_{2} \mathrm{NAs} / \mathrm{Ti}$ biosensors.

Acknowledgments: The present work has been carried out thanks to funds from “Secretaria d'Universitats i Recerca del Departament d'Economia i Coneixement de la Generalitat de Catalunya". The authors also wish to thank Francesc Broto from Institut Quimic de Sarria for the HPLC analysis.

Author Contributions: This work is a product of the intellectual collaboration of all authors. M.A. performed the experiments and wrote the manuscript; J.A. and S.C. supervised the work and reviewed manuscript.

Conflicts of Interest: The authors declare no conflict of interest.

\section{References}

1. Ventura, E.E.; Davis, J.N.; Goran, M.I. Sugar content of popular sweetened beverages based on objective laboratory analysis: Focus on fructose content. Obesity 2011, 19, 868-874. [CrossRef] [PubMed]

2. Ogden, C.L.; Carroll, M.D.; Kit, B.K.; Flegal, K.M. Prevalence of obesity and trends in body mass index among US children and adolescents, 1999-2010. JAMA 2012, 307, 483-490. [CrossRef] [PubMed]

3. Flegal, K.M.; Carroll, M.D.; Kit, B.K.; Ogden, C.L. Prevalence of obesity and trends in the distribution of body mass index among US adults, 1999-2010. JAMA 2012, 307, 491-497. [CrossRef] [PubMed]

4. OECD. Health at a Glance: Europe 2012; OECD Publishing: Paris, France, 2012.

5. Conzuelo, F.; Gamella, M.; Campuzano, S.; Ruiz, M.A.; Reviejo, A.J.; Pingarrón, J.M. An integrated amperometric biosensor for the determination of lactose in milk and dairy products. J. Agric. Food Chem. 2010, 58, 7141-7148. [CrossRef] [PubMed]

6. Kitikul, J.; Satienperakul, S.; Preechaworapun, A.; Pookmanee, P.; Tangkuaram, T. A Simple Flow Amperometric Electrochemical Biosensor Based on Chitosan Scaffolds and Gold Nanowires Modified on a Glassy Carbon Electrode for Detection of Glutamate in Food Products. Electroanalysis 2017, 29, 264-271. [CrossRef] 
7. Pilolli, R.; Monaci, L.; Visconti, A. Advances in biosensor development based on integrating nanotechnology and applied to food-allergen management. Trends Anal. Chem. 2013, 47, 12-26. [CrossRef]

8. European Commission; Directorate-General Joint Research Centre. Method-specific certification of free sugars and starch/glucose in two artificial food materials BCR-644, BCR-645. In Institute for Reference Materials and Measurements; European Commission-Joint Research Centre: Geel, Belgium, 2004.

9. The International Organisation of Vine and Wine. Method OIV-MA-AS311-02: Glucose and fructose. In Compendium of International Methods of Analysis of Wines and Musts; OIV: Paris, France, 2009; Volume 2, pp. $1-5$.

10. AOAC. Official Method 977.20: Separation of Sugars in Honey, Liquid Chromatographic Method. JAOAC 1977, 60, 838 .

11. AOAC. Official Method 982.14: Glucose, fructose, sucrose, and maltose in presweetened cereals; AOAC International: Gaithersburg, MD, USA, 1990.

12. Clark, L.C.; Lyons, C. Electrode systems for continuous monitoring in cardiovascular surgery. Ann. N. Y. Acad. Sci. 1962, 102, 29-45. [CrossRef] [PubMed]

13. Tang, H.; Chen, J.; Yao, S.; Nie, L.; Deng, G.; Kuang, Y. Amperometric glucose biosensor based on adsorption of glucose oxidase at platinum nanoparticle-modified carbon nanotube electrode. Anal. Biochem. 2004, 331, 89-97. [CrossRef]

14. Zhang, Z.; Xie, Y.; Liu, Z.; Rong, F.; Wang, Y.; Fu, D. Covalently immobilized biosensor based on gold nanoparticles modified $\mathrm{TiO}_{2}$ nanotube arrays. J. Electroanal. Chem. 2011, 650, 241-247. [CrossRef]

15. Wang, J. Nanomaterial-based electrochemical biosensors. Analyst 2005, 130, 421-426. [CrossRef] [PubMed]

16. Liu, S.; Fu, W.; Yang, H.; Li, M.; Sun, P.; Luo, B.; Yu, Q.; Wei, R.; Yuan, M.; Zhang, Y.; et al. Synthesis and Characterization of Self-Organized Oxide Nanotube Arrays via a Facile Electrochemical Anodization. J. Phys. Chem. C 2008, 112, 19852-19859. [CrossRef]

17. Xiao, P.; Garcia, B.B.; Guo, Q.; Liu, D.; Cao, G. $\mathrm{TiO}_{2}$ nanotube arrays fabricated by anodization in different electrolytes for biosensing. Electrochem. Commun. 2007, 9, 2441-2447. [CrossRef]

18. Feng, C.; Xu, G.; Liu, H.; Lv, J.; Zheng, Z.; Wu, Y. Glucose biosensors based on Ag nanoparticles modified $\mathrm{TiO} 2$ nanotube arrays. J. Solid State Electrochem. 2014, 18, 163-171. [CrossRef]

19. Yoriya, S.; Grimes, C. A Self-assembled $\mathrm{TiO}_{2}$ nanotube arrays by anodization of titanium in diethylene glycol: Approach to extended pore widening. Langmuir 2010, 26, 417-420. [CrossRef] [PubMed]

20. Grimes, C.A. Synthesis and application of highly ordered arrays of TiO2 nanotubes. J. Mater. Chem. 2007, 17, 1451-1457. [CrossRef]

21. Macak, J.M.; Hildebrand, H.; Marten-Jahns, U.; Schmuki, P. Mechanistic aspects and growth of large diameter self-organized $\mathrm{TiO}_{2}$ nanotubes. J. Electroanal. Chem. 2008, 621, 254-266. [CrossRef]

22. Mor, G.K.; Varghese, O.K.; Paulose, M.; Shankar, K.; Grimes, C.A. A review on highly ordered, vertically oriented $\mathrm{TiO} 2$ nanotube arrays: Fabrication, material properties, and solar energy applications. Sol. Energy Mater. Sol. Cells 2006, 90, 2011-2075. [CrossRef]

23. Cai, Q.; Paulose, M.; Varghese, O.K.; Grimes, C.A. The Effect of Electrolyte Composition on the Fabrication of Self-Organized Titanium Oxide Nanotube Arrays by Anodic Oxidation. J. Mater. Res. 2011, 20, 230-236. [CrossRef]

24. Pang, X.; He, D.; Luo, S.; Cai, Q. An amperometric glucose biosensor fabricated with Pt nanoparticle-decorated carbon nanotubes $/ \mathrm{TiO}_{2}$ nanotube arrays composite. Sens. Actuators B Chem. 2009, 137, 134-138. [CrossRef]

25. Gao, Z.-D.; Qu, Y.; Li, T.; Shrestha, N.K.; Song, Y.-Y. Development of Amperometric Glucose Biosensor Based on Prussian Blue Functionlized $\mathrm{TiO}_{2}$ Nanotube Arrays. Sci. Rep. 2014, 4, 1-7. [CrossRef] [PubMed]

26. Yang, Z.; Tang, Y.; Li, J.; Zhang, Y.; Hu, X. Facile synthesis of tetragonal columnar-shaped $\mathrm{TiO}_{2}$ nanorods for the construction of sensitive electrochemical glucose biosensor. Biosens. Bioelectron. 2014, 54, 528-533. [CrossRef] [PubMed]

27. Guisan, J.M. New Opportunities for Immobilization of Enzymes. In Inmobilization of Enzymes and Cells; Springer: Madrid, Spain, 2013; pp. 1-13. 
28. Basu, A.K.; Chattopadhyay, P.; Roychudhuri, U.; Chakraborty, R. A biosensor based on co-immobilized L-glutamate oxidase and L-glutamate dehydrogenase for analysis of monosodium glutamate in food. Biosens. Bioelectron. 2006, 21, 1968-1972. [CrossRef] [PubMed]

29. Gashtasbi, F.; Ahmadian, G.; Noghabi, K.A. New insights into the effectiveness of alpha-amylase enzyme presentation on the Bacillus subtilis spore surface by adsorption and covalent immobilization. Enzym. Microb. Technol. 2014, 64, 17-23. [CrossRef] [PubMed]

30. Gorton, L. Carbon paste electrodes modified with enzymes, tissues, and cells. Electroanalysis 1995, 7, $23-45$. [CrossRef]

31. Krajewska, B. Application of chitin- and chitosan-based materials for enzyme immobilizations: A review. Enzym. Microb. Technol. 2004, 35, 126-139. [CrossRef]

32. Wang, H.-S.; Pan, Q.-X.; Wang, G.-X. A Biosensor Based on Immobilization of Horseradish Peroxidase in Chitosan Matrix Cross-linked with Glyoxal for Amperometric Determination of Hydrogen Peroxide. Sensors 2005, 5, 266-276. [CrossRef]

33. Huang, Y.; Qin, X.; Li, Z.; Fu, Y.; Qin, C.; Wu, F.; Su, Z.; Ma, M.; Xie, Q.; Yao, S.; et al. Fabrication of a chitosan/glucose oxidase-poly(anilineboronic acid)-Au(nano)/Au-plated Au electrode for biosensor and biofuel cell. Biosens. Bioelectron. 2012, 31, 357-362. [CrossRef] [PubMed]

34. Kang, X.; Mai, Z.; Zou, X.; Cai, P.; Mo, J. A novel glucose biosensor based on immobilization of glucose oxidase in chitosan on a glassy carbon electrode modified with gold-platinum alloy nanoparticles/multiwall carbon nanotubes. Anal. Biochem. 2007, 369, 71-79. [CrossRef] [PubMed]

35. Hughes, G.; Pemberton, R.M.; Fielden, P.R.; Hart, J.P. The design, development and application of electrochemical glutamate biosensors. Trends Anal. Chem. 2015, 79, 106-113. [CrossRef]

36. Albanese, D.; Sannini, A.; Malvano, F.; Pilloton, R.; Di Matteo, M. Optimisation of Glucose Biosensors Based on Sol-Gel Entrapment and Prussian Blue-Modified Screen-Printed Electrodes for Real Food Analysis. Food Anal. Methods 2014, 7, 1002-1008. [CrossRef]

37. Fan, Y.; Hu, G.; Zhang, T.; Dong, X.; Zhong, Y.; Li, X.; Miao, J.; Hua, S. Determination of Glucose in Food by the Ionic Liquid and Carbon Nanotubes Modified Dual-Enzymatic Sensors. Food Anal. Methods 2016, 9 , 2491-2500. [CrossRef]

38. Monosik, R.; Stredansky, M.; Tkac, J.; Sturdik, E. Application of Enzyme Biosensors in Analysis of Food and Beverages. Food Anal. Methods 2012, 5, 40-53. [CrossRef]

39. Mansur, H.S.; Mansur, A.A.P.; Marques, M.E. Multi-enzymatic Systems with Designed 3D Architectures for Constructing Food Bioanalytical Sensors. Food Anal. Methods 2014, 7, 1166-1178. [CrossRef]

40. Rasiah, I.A.; Sutton, K.H.; Low, F.L.; Lin, H.; Gerrard, J.A. Crosslinking of wheat dough proteins by glucose oxidase and the resulting effects on bread and croissants. Food Chem. 2005, 89, 325-332. [CrossRef]

41. Goriushkina, T.B.; Soldatkin, A.P.; Dzyadevych, S.V. Application of amperometric biosensors for analysis of ethanol, glucose, and lactate in wine. J. Agric. Food Chem. 2009, 57, 6528-6535. [CrossRef] [PubMed]

42. Hobbs, J.M.; Patel, N.N.; Kim, D.W.; Rugutt, J.K.; Wanekaya, A.K. Glucose Determination in Beverages Using Carbon Nanotube Modi fi ed Biosensor: An Experiment for the Undergraduate Laboratory. J. Chem. Educ. 2013, 90, 1222-1226. [CrossRef]

43. Palmisano, F.; Rizzi, R.; Centonze, D.; Zambonin, P.G. Simultaneous monitoring of glucose and lactate by an interference and cross-talk free dual electrode amperometric biosensor based on electropolymerized thin films. Biosens. Bioelectron. 2000, 15, 531-539. [CrossRef]

44. Liao, Y.; Que, W. Preparation and photocatalytic activity of $\mathrm{TiO}_{2}$ nanotube powders derived by a rapid anodization process. J. Alloys Compd. 2010, 505, 243-248. [CrossRef]

45. Pardue, H.L.; Burke, M.F.; Jones, D.O. Reaction rate analysis and instrumentation: An experiment for the analytical laboratory. J. Chem. Educ. 1967, 44, 684. [CrossRef]

46. Clifford, E.; Toren, J. Determination of Glucose. A kinetics experiment for the analytical course. J. Chem. Educ. $1967,44,172-174$.

47. Berger, T.; Monllor-Satoca, D.; Jankulovska, M.; Lana-Villarreal, T.; Gómez, R. The electrochemistry of nanostructured titanium dioxide electrodes. ChemPhysChem 2012, 13, 2824-2875. [CrossRef] [PubMed] 
48. Shabir, G. A Validation of high-performance liquid chromatography methods for pharmaceutical analysis. Understanding the differences and similarities between validation requirements of the US Food and Drug Administration, the US Pharmacopeia and the International Conf. J Chromatogr. A 2003, 987, 57-66. [CrossRef] [PubMed]

49. Ermer, J.; Nethercote, P. Method Validation in Pharmaceutical Analysis: A Guide to Best Practice, 2nd ed.; Ermer, J., Nethercote, P., Eds.; Wiley-VCH Verlag GmbH \& Co. KGaA: Weinheim, Germany, 2015, ISBN 9780470467091.

50. Li, C.; Liu, Y.; Li, L.; Du, Z.; Xu, S.; Zhang, M.; Yin, X.; Wang, T. A novel amperometric biosensor based on $\mathrm{NiO}$ hollow nanospheres for biosensing glucose. Talanta 2008, 77, 455-459. [CrossRef] [PubMed]

51. Kang, Q.; Yang, L.; Cai, Q. An electro-catalytic biosensor fabricated with Pt-Au nanoparticle-decorated titania nanotube array. Bioelectrochemistry 2008, 74, 62-65. [CrossRef] [PubMed]

52. Lin, Y.; Hu, L.; Yin, L.; Guo, L. Electrochemical glucose biosensor with improved performance based on the use of glucose oxidase and Prussian Blue incorporated into a thin film of self-polymerized dopamine. Sens. Actuators B Chem. 2015, 210, 513-518. [CrossRef]

53. Kong, F.Y.; Gu, S.X.; Li, W.W.; Chen, T.T.; Xu, Q.; Wang, W. A paper disk equipped with graphene/polyaniline/Au nanoparticles/glucose oxidase biocomposite modified screen-printed electrode: Toward whole blood glucose determination. Biosens. Bioelectron. 2014, 56, 77-82. [CrossRef] [PubMed]

54. Esmaeili, C.; Abdi, M.; Mathew, A.; Jonoobi, M.; Oksman, K.; Rezayi, M. Synergy Effect of Nanocrystalline Cellulose for the Biosensing Detection of Glucose. Sensors 2015, 15, 24681-24697. [CrossRef] [PubMed]

55. Tao, J.Z.; Xu, G.R.; Hao, H.L.; Yang, F.X.; Ahn, K.S.; Lee, W.Y. Poly(m-phenylenediamine)-Prussian blue hybrid film formed by one-step electrochemical deposition for glucose biosensor. J. Electroanal. Chem. 2013, 689, 96-102. [CrossRef]

56. Chandra Sekar, N.; Mousavi Shaegh, S.A.; Ng, S.H.; Ge, L.; Tan, S.N. A paper-based amperometric glucose biosensor developed with Prussian Blue-modified screen-printed electrodes. Sens. Actuators B Chem. 2014, 204, 414-420. [CrossRef]

57. Shen, X.; Xia, X.; Du, Y.; Ye, W.; Wang, C. Amperometric Glucose Biosensor Based on AuPd Modified Reduced Graphene Oxide/Polyimide Film with Glucose Oxidase. J. Electrochem. Soc. 2017, 164, B285-B291. [CrossRef]

58. Bäcker, M.; Rakowski, D.; Poghossian, A.; Biselli, M.; Wagner, P.; Schöning, M.J. Chip-based amperometric enzyme sensor system for monitoring of bioprocesses by flow-injection analysis. J. Biotechnol. 2013, 163, 371-376. [CrossRef] [PubMed]

59. Geddes, C.D.; Lakowicz, J.R. Glucose Sensing; Springer: Berlin, Germany, 2006; ISBN 9780387330150.

60. AOAC. Peer-Verified Methods Program, Manual on Policies and Procedures. Available online: http:/ / citese erx.ist.psu.edu/viewdoc/download?doi=10.1.1.196.7223\&rep=rep1\&type=pdf (accessed on 1 October 2017).

61. AOAC. Definitions and Calculations of Horrat Values From Intralaboratory Data. 2004. Available online: http:/ / www.readbag.com/aoac-dietsupp6-dietary-supplement-web-site-horrat-slv (accessed on 1 October 2017).

62. Mcpolin, O. Validation of Analytical Methods for Pharmaceutical Analysis. Events 2009, 44, 1-141. [CrossRef]

63. AOAC. Standard Format and Guidance for AOAC Standard Method Performance Requirement (SMPR) Documents. 2011. Available online: http:/ / www.aoac.org/aoac_prod_imis/AOAC_Docs/ISPAM/3.5SMP RGuidelinev12.1.pdf (accessed on 1 October 2017).

64. Vasilarou, A.-M.G.; Georgiou, C.A. Enzymatic Spectrophotometric Reaction Rate Determination of Glucose in Fruit Drinks and Carbonated Beverages. An Analytical Chemistry Laboratory Experiment for Food Science-Oriented Students. J. Chem. Educ. 2000, 77, 1327. [CrossRef]

65. Yoo, E.-H.; Lee, S.-Y. Glucose biosensors: an overview of use in clinical practice. Sensors 2010, 10, 4558-4576. [CrossRef] [PubMed]

66. Guo, X.; Liang, B.; Jian, J.; Zhang, Y.; Ye, X. Glucose biosensor based on a platinum electrode modified with rhodium nanoparticles and with glucose oxidase immobilized on gold nanoparticles. Microchim. Acta 2014, 181, 519-525. [CrossRef]

67. Yakovleva, M.; Buzas, O.; Matsumura, H.; Samejima, M.; Igarashi, K.; Larsson, P.O.; Gorton, L.; Danielsson, B. A novel combined thermometric and amperometric biosensor for lactose determination based on immobilised cellobiose dehydrogenase. Biosens. Bioelectron. 2012, 31, 251-256. [CrossRef] [PubMed]

68. Kang, X.; Mai, Z.; Zou, X.; Cai, P.; Mo, J. Glucose biosensors based on platinum nanoparticles-deposited carbon nanotubes in sol-gel chitosan/silica hybrid. Talanta 2008, 74, 879-886. [CrossRef] [PubMed] 
69. Campuzano, S.; Loaiza, O.A.; Pedrero, M.; de Villena, F.J.M.; Pingarrón, J.M. An integrated bienzyme glucose oxidase-fructose dehydrogenase-tetrathiafulvalene-3-mercaptopropionic acid-gold electrode for the simultaneous determination of glucose and fructose. Bioelectrochemistry 2004, 63, 199-206. [CrossRef] [PubMed]

70. Ammam, M.; Fransaer, J. Two-enzyme lactose biosensor based on $\beta$-galactosidase and glucose oxidase deposited by AC-electrophoresis: Characteristics and performance for lactose determination in milk. Sens. Actuators B Chem. 2010, 148, 583-589. [CrossRef]

(c) (c) 2017 by the authors. Licensee MDPI, Basel, Switzerland. This article is an open access article distributed under the terms and conditions of the Creative Commons Attribution (CC BY) license (http:// creativecommons.org/licenses/by/4.0/). 